\title{
The I DO project: using experiential service learning to increase the impact of PIS
}

\author{
Sherwin Husseinifard and Lennart Corleissen \\ Erasmus University Rotterdam, Rotterdam School of Management, \\ Rotterdam, The Netherlands, and \\ Lucas Meijs \\ Department of Business-Society Management, \\ Rotterdam School of Management, Rotterdam, The Netherlands
}

\section{Experiential service learning}

\begin{abstract}
Purpose - The I DO project connects business students to the European branch of small private international development organizations (PIs), using experiential service learning, which combines skill-based and hands-on volunteering opportunities, to achieve learning objectives with students (learning) while helping PIs (service). This paper aims to summarize the experiences and learnings of the pilot project.

Design/methodology/approach - Students work in four-person teams, guided by a student-coach, an academic supervisor and professional support, on a service project for one PI. Students provide indirect service to the PI through skill-based activities (e.g. creating marketing strategies or improving organizational efficiency) or hands-on volunteering (e.g. fundraising). In this program, students do not provide direct service to beneficiaries (i.e. they do not travel abroad). "I DO" will be established as a scalable regular course within the RSM Bachelor's program. A pilot involving 22 students and 6 PIs was started in September 2020.

Findings - The teaching brief describes lessons learned from the non-credit bearing 2021 pilot. As skillbased volunteers, students performed hands-on support tasks, conducted analyses, and formulated strategic recommendations. In the pilot, however, the students did not take on the active role of skill-based volunteer consultants, concentrating instead on the safer, easier role of hands-on support volunteers. Future improvements could thus be realized in the preparation phase, as well as by focusing the guidance of the coaches and academic supervisor on the stated learning objectives. The project and the students' motivation were negatively affected by the lockdown. In the future, including after the pandemic, measures will be added to maintain motivation, including a focus on the personal development of students, social events between students and stronger involvement on the part of the coach.
\end{abstract}

Originality/value - The teaching brief presents a new approach to service learning in international development as the service is giving to Western "headquarters" in both hands-on as skill-based volunteering.

Keywords Volunteering, Service learning, Nonprofit

Paper type General review

\section{Introduction}

According to a survey and focus groups conducted as part of the International Marketing Research course at RSM, students are clearly motivated to fight societal problems and take

(C) Sherwin Husseinifard, Lennart Corleissen and Lucas Meijs. Published by Emerald Publishing Limited. This article is published under the Creative Commons Attribution (CC BY 4.0) licence. Anyone may reproduce, distribute, translate and create derivative works of this article (for both commercial and non-commercial purposes), subject to full attribution to the original publication and authors. The full terms of this licence may be seen at http://creativecommons.org/licences/by/4.0/legalcode
Received 2 March 2021 Revised 27 April 2021 10 May 2021 Accepted 18 May 2021 
JGR

13,1

on challenges, including as part of their formal education. The COVID-19 pandemic apparently enhanced this motivation. Whereas many students are already attempting to have an impact through extracurricular activities, such efforts are not embedded within the university context. In addition to expanding possibilities for student activities, such embeddedness could add more practical experiences to the curriculum. To this end, the student association Students for Project Misside [1] developed the I DO project for the curriculum of the Bachelor of (International) Business Administration ((I)BA) program at the Rotterdam School of Management (RSM), advised by the Chair on Strategic Philanthropy and Volunteering, university learning consultants, and program management. In this teaching brief we describe the structure, set-up and results of I Do project and present some lessons learned.

\section{Structure and set-up of the pilot}

Structure

The I DO project uses service learning (Bringle et al., 2013) to connect business students to small Dutch private international aid organizations (PIs) (volunteer run organizations with limited paid staff (Kinsbergen, 2014) to achieve learning objectives while consulting with the boards (and employees, if any) of PIs. To ensure the influx of new PIs each year (as required for the consultancy objective), PIs are selected with the help of a national umbrella organization, Partin [2].

A pilot (non-credit bearing) was started in September 2020, involving 22 second-year (I) BA Students, six PIs, six student-coaches (third-year and Master's students) and academic staff [3]. The students worked in four-person teams. All of the PIs were operating aid projects in developing countries, but maintained headquarters in The Netherlands/Europe. The core idea of the project is for a team of students to support the Dutch/European component of a PI through activities performed in The Netherlands (e.g. marketing, fundraising, organizational efficiency). It thus centers on indirect volunteer service (Meijs and Brudney, 2007) - helping the PI, without contact with beneficiaries - in contrast to direct volunteer service, which does involve direct contact with beneficiaries. In addition, and following the example of corporate volunteering, students perform skill-based volunteering as consultants, combined with hands-on volunteering (e.g. by operating socialmedia channels or organizing fundraisers Roza et al., 2017). While not particularly innovative from a global perspective, the concept is quite innovative within the context of Dutch universities. The focus on using knowledge and expertise gained during the first two years of the participants' business studies is also a novel element, as similar projects have tended to regard participating students purely as hands-on volunteers.

Lectures, workshops, trainings, readings and assignments are organized to support students and encourage a broader mindset. Each team is led by a "coach": a third-year or Master's student. The idea of assigning advanced students with responsibility for a group of less advanced students was inspired by existing mentor programs for first-year students. In the I DO project, advanced students actively lead teams of less advanced students in collaboration with external stakeholders (i.e. the PIs). Coaches ensure that stakeholder expectations are met, communication proceeds well, collaborative impact is created, and students experience both professional and personal growth. They serve as leaders for the students and as a liaison between the students and the PIs.

\section{Set-up}

The pilot has a three-part structure: preparation (1 month), action (6-8 months) and evaluation (1 month). Due to COVID-19, the pilot was operated in a fully digital environment. In the preparation phase, students get to know their team members and "their" PI. This 
phase starts with workshops to welcome students and introduce the concepts and characteristics of the PIs. During the first weeks of the collaboration phase, the PIs assign specific hands-on tasks to the students, who are also expected to move into the role of independent volunteer consultants, seeking ways to improve the operations of the PIs. Each student is encouraged to develop expertise in a specific area/theme needed by the PI (e.g. marketing, data analytics, strategy), possibly corresponding to the future choice of a Master's program. Workshops are held to support the students, improve their collaboration with PIs and broaden their understanding of topics relating to PIs/NGOs. The workshops address such topics as social-media marketing, big data in humanitarian challenges and fundraising. In the evaluation phase, each team is expected to write a final report, which is also intended to help the PI to implement the findings.

\section{Objectives of the course}

Like all service learning courses (Aramburuzabala et al., 2019), the I Do project involves objectives for students, the university, and the community (PIs). From the student perspective, I DO offers a real-life opportunity to translate learning into practice, and vice versa. To connect theory to practice, the project adopts an experiential learning approach (Kolb, 1984) to apply and refine the students' leadership compass, thus learning what it means to take responsibility and be proactive. The tangible impact that students experience when working for a PI cultivates their ethical and sustainable behavior. Once the project is credit-bearing, the learning objectives will call for students to demonstrate analytical skills, as well as skills in the creation, design and evaluation of solutions, drawing on knowledge acquired during the Bachelor's program. Students must demonstrate their ability to define and interpret the stated problem based upon relevant societal, scientific, and ethical aspects, in addition to selecting relevant information to substantiate their analysis and proposed solutions. In terms of attitude and skills development, students are expected to define their personal learning goals and gather documentation on their personal and professional development.

For RSM, the I DO project offers an effective use of educational time to fulfill the RSM mission of being a force for positive change. Academic guidance and workshop participation are organized to facilitate learning. The project is also an experiment in impact-driven education.

For PIs, I DO will result in professional advice formulated by student-volunteer consultants, combined with tangible operational support in indirect service provided by the same students. The goal is to help PIs advance in their organizational development.

\section{Results}

To improve the pilot, we assessed the progress by quantitative surveys to gather general opinions and satisfaction levels, followed by interviews addressing specific problems, ideas and suggestions. Regular discussions were also held with everyone involved.

In December 2020 and April 2021, we conducted surveys and subsequent in-depth interviews with all pilot PIs. The surveys included questions concerning satisfaction with the student team, the coach and others. To maximize response, the survey was kept short (see Appendix), as were the interviews. Finally, we asked the organizations for suggestions about improvements for the pilot and the further course development.

Throughout the pilot, we held bi-weekly discussion-groups with the coaches. In these sessions, the coaches provided updates on the progress of their teams, asked questions, exchanged suggestions on specific problems and shared ideas and best practices. The organizing team further informed the coaches about recent developments and asked them for 
JGR

13,1

detailed feedback on all areas of the course. Significant developments or problems (e.g. updates on course structure, workshop scheduling) were addressed in the group. To promote bonding between coaches, many social gatherings were organized, in which critical topics and ideas were exchanged, to be addressed later in the official meetings.

Two feedback sessions were conducted with each participant. The interviews followed a structure comparable to that of the organization interviews, covering general questions, specification of problems and ideas, and a request for constructive feedback. In the second session, students were asked to share their opinions about the current state of the course development.

We conducted three feedback sessions with each team, under the academic supervision of the RSM Professor "Strategic Philanthropy and Volunteering". This allowed the students to receive professional and academic feedback, while providing the organizing team with an indication of the students' progress and ability to present their results. Perceptions of each workshop were measured by a short quantitative questionnaire, which allowed us to assess and test various workshop layouts and designs (see Appendix).

\section{Feedback: structure and set-up}

The stakeholders' feedback on the structure and set-up of the project was generally positive. The PIs were pleased with the hands-on efforts of the student teams. Differences in the expectations of the students and the PIs nevertheless generated at least temporary dissatisfaction for both parties. In the starting period, most PIs regarded the student teams purely as hands-on volunteers, thereby hindering them from realizing their potential as skills-based volunteers. Moreover, the preparation phase did not equip the students with sufficient ability and confidence to act as volunteer consultants. This was addressed by enhancing the students' skill sets and addressing their professional attitude in several workshops and individual sessions. The leadership role of the coaches was strengthened as well. Although the work of the student teams will never consist entirely of consulting (as they will still perform hands-on tasks), the PIs now expect to benefit from the businessschool background of the students. Another problem had to do with fitting the rhythm of PIs into the university schedule. Unlike students, PIs have no clearly defined vacation or exam periods.

As noted above, the COVID-19 pandemic had a substantial impact on the pilot project. The lack of physical contact weakened team dynamics, communication and trust. This was also the case for the relationships between the teams and the PIs, making it more difficult for the teams to gain the trust of the organizations. The workshops and individual training further lacked the needed interactivity. Finally, the pandemic complicated the creation of a general "I DO community," with cross-team information exchange and collaboration. We addressed these issues by deepening the involvement of the coaches and team-building sessions involving reflection on strengths and weaknesses, in addition to establishing team roles and rules. The I DO community was further strengthened by the organization of virtual social events with all students.

\section{Student perspective}

The students were able to put theory into practice when analyzing the organization. They discovered the utility of academic models. Nevertheless, as expected, they encountered difficulties in executing the projects and applying theory and prior knowledge. The students were neither proactive nor comfortable engaging in problem-solving and uncertain situations in these real-life cases. In their education, they are used to following specific guidelines and steps to attain satisfactory results in predictable, "dead" cases. In the future, 
the student role and expectations should be clarified further. In the pilot, students spent too much time and effort in the role of hands-on volunteers. Although this was crucial to gaining the organization's trust and gathering vital information, it made the students overly dependent on the organizations instead of independently looking for ways to advise and improve them. In some cases, the relative professionalism of the PI posed a problem. Some PIs (essentially part-time organizations) were too small for the volunteer consultancy of the students to be sufficiently beneficial. This was potentially detrimental to student motivation. On the other hand, such situations offer excellent opportunities to practice and learn how to resolve them. Finally, the I DO project raised environmental awareness for all participants.

\section{University perspective}

The university's resources were used to combine student development with positive external impact. The educational instruments of workshops and individual/team feedback sessions were important as well. In the future, more plenary and more specific team-based workshops and teaching will be implemented. In the spirit of the pilot, the students participated in the creation of the "real" I DO. The "Mini-Hackathons" with students, coaches, and learning innovators were fruitful and motivated the students. In these sessions, students shared their opinions on the project and its process in a more structured manner, supported by the educational experts who facilitated the discussion. For the university, the project generated insights for the development of future assessment methods and learning goals, in collaboration with Students for Project Misside.

\section{Private international development organization perspective}

As reported above, miscommunication about the role of the student initially caused some inefficiency. Nevertheless, the students were ultimately able to provide useful, interesting advice on business-related topics. The ability to summarize and incorporate knowledge acquired from research and other sources into science-based advice proved a major asset that the students could offer to the PIs. The students were also able to take over and improve some operations. In the future, it might be interesting to assign a more specific role to Partin, the umbrella organization, with regard to the preparation of both students and PIs.

\section{Lessons learned}

\section{Structure and initiation}

Based on the experiences of the pilot, the structure of the course will be altered to have three months of preparation, six months of action and one month of evaluation. In the preparation phase, students can develop hard and soft skills, while creating an analysis of the organization, resulting in an action plan. This will allow the planning and structuring of the academic schedule and provide an initial assessment method. When engaging in experiential learning within this complex situation, therefore, students will be guided more closely in the beginning, while establishing contact with the PIs, thus maximizing the potential for both service and learning. The authors recommend communicating expectations directed toward students very clearly.

Academic guidance is also needed to verify whether PIs are "complex" enough to ensure that the students' advice can be heard, understood and potentially implemented. For the action phase, a more nuanced strategy for combining skill-based and hands-on volunteering is needed. The authors recommend investing many resources in the initial process, thus helping to develop a network of sufficiently "complex" PIs, that can grow naturally in subsequent years.
Experiential service learning 
JGR

13,1

\section{Maintaining motivation}

Preventing student demotivation requires more interaction and connection through teambuilding, one-to-one feedback and social events (either online or in person) to create a comfortable student community. Furthermore, when offering experiential learning opportunities, students should be involved in the development and further improvement of the course. They should be co-creators, and not merely participants. Moreover, the greatest source of inspiration for students is the ability to create a tangible impact requiring a balance between skill-based and hands-on volunteering. For learning purposes, it is essential to help students reflect on their outcomes and successes, while providing constructive feedback for mistakes. Finally, intervision sessions should be organized to promote information-sharing between teams regarding new ideas and approaches to solving common problems.

\section{Importance of the coach}

A professional and capable coach who coordinates, facilitates, motivates and uncovers potential problems is of utmost importance. The professionalism and knowledge of the coaches increase the confidence with which the teams act. This should be considered when developing the process of selecting, preparing and training of student-coaches in subsequent years. Coaches should receive extensive leadership training before each phase and responsibility throughout the project. RSM is currently developing a leadership course that combines a theoretical (learning) and a practical (coaching) component.

\section{Service learning}

Reflection on the development of I DO is partly directed toward the development of a new course, but it also concerns the inherent processes of service learning. To be an effective in promoting learning, the experiences must take students somewhat out of their comfort zone, while providing good reflection and, most importantly, having a substantial duration. From this perspective, I DO should retain its relatively long duration, avoid curtailing the initial "getting to know each other" phase, and organize a higher level of reflection on the student learning and impact (Eyler and Giles, 1999). For most students, the experience of collaborating with a PI is sufficiently out of the comfort zone.

\section{Conclusion}

Service-learning projects like I DO offer great possibilities for actively linking business schools to the environment in a way that enhances education. They also have the potential to fill gaps in business expertise for smaller PIs, which are usually led by small, passionate, yet overburdened volunteer boards. In retrospect, student motivation is the most crucial factor in the success of a team. Considerable effort should therefore be dedicated to maintaining the initial high level of motivation. Based on the experiences of the pilot, this can be achieved by adequately preparing students for their roles with regard to the unique characteristics of PIs and the tasks that will be expected. Moreover, students should be closely guided during the first weeks, such that they become accustomed to the new, complex environment of the PIs. This also emphasizes the importance of the coaches to the success of their teams. In conclusion, I DO highlights that students need not be sent abroad to support international development. Supporting European branches of aid organizations with analyses, strategic advice and tangible operational support can be valuable to PIs, as demonstrated by the impact of the pilot. The authors would welcome any opportunities to engage in sharing information or collaborating with other universities and educators to benefit service-learning, aid organizations (PIs) and academic research (particularly in the field of business). 


\section{Notes}

1. www.students-for-project-misside.org/

2. https://partin.n1/

3. Beginning in the 2021/2022 academic year, I DO will be credit-bearing.

\section{References}

Aramburuzabala, P., McIlrath, L. and Opazo, H. (Eds) (2019), Embedding Service Learning in European Higher Education: Developing a Culture of Civic Engagement, Routledge.

Bringle, R.G., Clayton, P.H. and Hatcher, J.A. (2013), "Research on service learning", Research on Service Learning: Conceptual Frameworks and Assessment: Communities, Institutions, and Partnerships, Vol. 2, p. 335.

Eyler, J. and Giles, D.E. Jr (1999), Where's the Learning in Service-Learning? Jossey-Bass Higher and Adult Education Series, Jossey-Bass, Sansome St., San Francisco, CA.

Kinsbergen, S. (2014), "Behind the pictures: understanding private development initiatives", Doctoral dissertation, Radboud University Nijmegen.

Kolb, D.A. (1984), Experiential Learning: Experience as the Source of Learning and Development, Prentice-Hall, NJ.

Meijs, L.C.P.M. and Brudney, J.L. (2007), "Winning volunteer scenarios: the soul of a new machine", International Journal of Volunteer Administration, Vol. 24 No. 6, pp. 68-79.

Roza, L., Shachar, I., Meijs, L. and Hustinx, L. (2017), "The nonprofit case for corporate volunteering: a multi-level perspective", The Service Industries Journal, Vol. 37 Nos 11/12, pp. 746-765.

\section{Appendix}

Public references

I DO LinkedIN Page:

www.linkedin.com/company/i-do-project

EUR General Article on I DO:

www.eur.nl/en/impactatthecore/news/course-impact-what-happens-when-students-say-i-do

EUR Interview with a Pilot PI:

www.eur.nl/en/impactatthecore/news/how-society-benefits-impact-education-more-potential-

donors-we-anticipated

Regular Satisfaction Survey (PIs)

(1) In two or three sentences, please describe the overall progress of the project between January and March. | Open Question

(2) How would you rate your overall satisfaction with the I DO Project since the beginning of 2021? | 10-Point Likert Scale

(3) How would you rate the communication between you and the coach responsible for your association? (e.g., in terms of openness, approachability, structure) | 10-Point Likert Scale

(4) Have you faced any additional challenges since the last feedback session? If so, please summarize these challenges in three sentences. | Open Question

(5) How satisfied were you with the external-relations teams in IDO? | 10-Point Likert Scale

(6) Would you like to disclose your insights, or would you prefer to keep them confidential within the external relations team? | disclose/keep confidential 
JGR

13,1

28

\section{Post-Workshop Questionnaire}

Five-point Likert scale (strongly disagree - strongly agree)

(1) My overall impression of the workshop is positive.

(2) The content of the workshop was relevant and comprehensible.

(3) The workshop provided a good balance between listening and activities.

(4) The breakout rooms were well placed and helped to facilitate the discussion.

(5) The guest speaker added value to the discussion.

Open questions

(1) What would you have about the workshop?

(2) If you have any other comments (positive or negative), please share them with us here.

\section{Corresponding author}

Lucas Meijs can be contacted at: lmeys@rsm.nl

For instructions on how to order reprints of this article, please visit our website: 